\title{
Variation in reported experience of involvement in cancer treatment decision making: evidence from the National Cancer Patient Experience Survey
}

\author{
A El Turabi ${ }^{*}, 1$, G A Abel ${ }^{1}$, M Roland ${ }^{1}$ and G Lyratzopoulos ${ }^{1}$ \\ ${ }^{1}$ Cambridge Centre for Health Services Research, Department of Public Health and Primary Care, University of Cambridge, \\ Forvie Site, Robinson Way, Cambridge, CB2 OSR, UK
}

Background: Exploring variation in patients' experiences of involvement in treatment decision making can identify groups needing extra support, such as additional consultation time, when considering treatment options.

Methods: We analysed data from the 2010 English National Cancer Patient Experience Survey, a national survey of all patients attending hospitals in England for cancer treatment over a 3-month period, to examine how experience of involvement in decisions about treatment varied between patients with 38 different primary cancers using logistic regression. We analysed responses from 41411 patients to a single question examining patient experience of involvement in treatment decision making. We calculated unadjusted odds ratios of reporting the most positive experience between patients of different sociodemographic and tumour characteristics and explored the effects of adjusting for age, gender, ethnicity, deprivation, cancer type and hospital of treatment.

Results: Of the 41441 respondents, 29776 (72\%) reported positive experiences of decision-making involvement. Younger patients reported substantially less positive experiences of involvement in decision making (adjusted $O R=0.49$ 16-24 vs 65-74; $P<0.001$ ), as did ethnic minorities (adjusted ORs $=0.52,0.62$ and 0.73 for Black, Chinese and Asian vs White patients, respectively; $P<0.001$ ). Experience varied considerably between patients with different cancers ( e.g., $O R=0.52$ for anal and 1.37 for melanoma vs colon cancer; $P<0.001$ ), with ovarian, myeloma, bladder and rectal cancer patients reporting substantially worse experiences compared with other patients with gynaecological, haematological, urological and colorectal cancers, respectively. Clustering of different patient groups within hospitals with outlying performance report scores could not account for observed differences.

Conclusion: Efforts to improve involvement in treatment decision making can focus on those who report the worst experience, in particular younger patients, ethnic minorities and patients with rectal, ovarian, multiple myeloma and bladder cancer.

Modern health-care systems rightly consider shared decision making (i.e., effectively involving patients in decisions about their treatment) to be an essential component of patient-centred care (Committee On Quality Of Health Care In America, 2001; Secretary of State for Health, 2010; Barry and Edgman-Levitan,
2012; Stiggelbout et al, 2012) and cancer care in particular (Epstein and Street, 2007). More positive experiences of involvement in cancer treatment decision making are associated with reduced decisional conflict (i.e., patient-reported difficulty in making decisions), greater satisfaction with treatment decisions and

${ }^{\star}$ Correspondence: Dr A El Turabi; E-mail: ae300@medschl.cam.ac.uk

Previous presentations of related work: El Turabi, A: Variations in satisfaction with involvement in decisions about cancer treatment: analysis of the National Cancer Patient Experience Survey 2010. Presented at the National Cancer Intelligence Network Cancer Outcomes Conference, Birmingham, UK, June 14-15, 2012.

Received 19 February 2013; revised 26 May 2013; accepted 3 June 2013;

published online 27 June 2013

(c) 2013 Cancer Research UK. All rights reserved 0007-0920/13

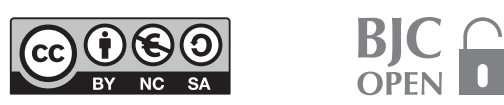




\section{Box 1 The Cancer Patient Experience Survey-key facts.}

The 2010 English National Health Service Cancer Patient Experience Survey (NCPES) is one of the largest surveys of experience of cancer patients in any country.

- Conducted on behalf of the English Department of Health with the aims of monitoring national progress in cancer care and driving quality improvements locally.

- Sent to all adult patients with a primary diagnosis of cancer who were treated in a hospital as inpatient or day-case patients in the first quarter of 2010.

- Excluded non-NHS (private) patients, patients not resident in the United Kingdom and patients who had died before surveys were distributed.

- Postal survey with two reminders for nonrespondents.

- Sent to 101773 unique patients; 67713 responded (67\% response rate).

- Contained 59 evaluative questions covering 15 aspects of patients' experiences of care.

- Four rounds of cognitive testing undertaken to improve the comprehensibility, acceptability and reliability of question items (Quality Health, 2010a).

- Results reported nationally and for each hospital and by 13 major cancer groups (Department of Health, 2010a; Quality Health, 2010b).

improved patient well-being (Gattellari et al, 2001; Keating et al, 2002; Brown et al, 2012). Although patients with different sociodemographic characteristics tend to report variable experiences of care (Campbell et al, 2001; Weech-Maldonado et al, 2003; Goldstein et al, 2009; Mead and Roland, 2009; Elliott et al, 2010; Lyratzopoulos et al, 2012a), relatively little is known about how the experience of shared decision making varies between patients with cancers (Hubbard et al, 2008). Understanding such variation can help identify patient groups who may require additional time and support in making decisions about their treatment (Friedberg et al, 2013).

Previous studies have used patient survey data to describe and explore possible reasons for sociodemographic disparities in patient experience of primary and hospital care (Rodriguez et al, 2009; Elliott et al, 2010; Lyratzopoulos et al, 2012a). Until recently, however, few large national surveys of sufficient quality had been conducted to enable a robust analysis of the experiences of cancer patients, and previous relevant evidence is constrained in relation to sample size and number of studied cancers (Hubbard et al, 2008; Ayanian et al, 2010).

The English National Health Service Cancer Patient Experience Survey 2010 is one of the largest surveys of cancer patient experience ever undertaken (Box 1) (Department of Health, 2010a). Using data from this survey, we sought to examine whether patient experience of involvement in treatment decision making varied between patients of different age, gender, ethnicity, socioeconomic deprivation and cancer diagnosis. We also sought to establish whether any observed differences might be accounted for by clustering of patient groups reporting less positive experiences in poorly performing hospitals.

\section{MATERIALS AND METHODS}

Participants and data. We analysed data from the 2010 National Cancer Patient Experience Survey (NCPES) (Department of Health, 2010b). These included data on patients' responses to survey questions, sociodemographic characteristics and primary cancer diagnosis. All patients received the survey in the first half of 2010 having attended hospital for management of their cancer between January and March of the same year, although answers given may refer to a different period. The majority of analysed respondents $(66 \%)$ indicated that they were diagnosed in the last year. We used respondent-reported information on patients' gender, age and ethnicity (2001 Census Office for National Statistics (ONS) ethnicity classification). Data on patient area deprivation (Index of Multiple Deprivation 2007 score of patients' lower super output area of residence) (Noble et al, 2007) and cancer diagnosis were derived by the survey provider from hospital administrative records. Cancer diagnoses were defined according to the International Classification of Diseases 10 codes (Supplementary Appendix 1). We categorised respondents into eight age groups and six ethnic groups based on ONS classification (Supplementary Appendix 2), and defined patients' national (England) deprivation quintiles (quintile-defining points: 8.257, 13.525, 20.741 and 33.511).

We analysed responses to the single NCPES question evaluating the experience of involvement in decisions about treatment: 'Were you as involved in decisions about which treatment you would have as you wanted?' Respondents with a diagnosis of a known primary cancer were included in our analysis if they provided an informative response to this question and had completely observed data on all sociodemographic variables.

Statistical analysis. Measures of patient experience included in NCPES are reported publicly, both for England as a whole and also by each hospital, and fed back to health service managers and clinical teams using binary categorisations for more or less positive patient experience (Department of Health, 2010a; Quality Health, 2010b). In such reports the measure of patient experience of involvement in decision making about treatment compares the most positive responses to the question ('Yes, definitely') with less positive responses ('Yes, to some extent', 'No, but I would like to have been more involved'). Uninformative responses ('Only one type of treatment was suitable for $m e$ ') are excluded. Accordingly, we used this binary outcome to explore variation in experience of involvement in treatment decision making between different patient groups. We also examined alternative binary definitions of this item in sensitivity analysis.

We described the proportion of patients in each sociodemographic group and cancer type who reported the most positive experience of involvement in treatment decision making and calculated respective unadjusted odds ratios using logistic regression (model 1). To examine whether any observed variation was because of confounding by patient factors, we then adjusted for all observed sociodemographic variables and cancer type using a multivariable fixed-effects logistic regression model (model 2). Then, to examine whether any variation was explained by clustering of patients from certain groups in hospitals with lower or higher than average performance, we constructed a mixedeffects model, augmenting model 2 with a random effect (intercept) for hospital of treatment (model 3).

Using post hoc comparisons derived from model 3, we examined how reported experience of involvement in treatment decision making varied between cancers treated by the same cancer specialty teams. This within-specialty variation may provide further insights about the potential sources of observed variation. After adjusting for patient characteristics, variations between cancers treated by the same specialty teams are more plausibly explained by differences in disease factors, such as diagnostic and treatment pathways, severity of illness and prognosis, than differences in the way that health-care professionals might involve patients in decision making. 
Table 1. Patient experience of involvement in decision making about treatment

\begin{tabular}{|c|c|c|c|c|c|c|c|c|c|c|}
\hline & & \multicolumn{3}{|c|}{$\begin{array}{l}\text { Unadjusted odds of reporting } \\
\text { most positive experience of } \\
\text { shared decision making } \\
\text { (model 1) }\end{array}$} & \multicolumn{3}{|c|}{$\begin{array}{l}\text { Odds adjusted for } \\
\text { patient characteristics } \\
\text { (model 2) }\end{array}$} & \multicolumn{3}{|c|}{$\begin{array}{l}\text { Odds adjusted for patient } \\
\text { characteristics and hospital } \\
\text { (model } 3 \text { ) }\end{array}$} \\
\hline & $\begin{array}{c}\% \\
\text { Reporting } \\
\text { most } \\
\text { positive } \\
\text { experience }\end{array}$ & $\begin{array}{l}\text { Odds } \\
\text { ratio }\end{array}$ & $95 \% \mathrm{Cl}$ & $P$-value* & $\begin{array}{l}\text { Odds } \\
\text { ratio }\end{array}$ & $95 \% \mathrm{Cl}$ & $\boldsymbol{P}$-value ${ }^{*}$ & $\begin{array}{l}\text { Odds } \\
\text { ratio }\end{array}$ & $95 \% \mathrm{Cl}$ & $\boldsymbol{P}$-value* \\
\hline \multicolumn{11}{|l|}{ Gender } \\
\hline $\begin{array}{l}\text { Male }(n=19566) \\
\text { Female }(n=21875)\end{array}$ & $\begin{array}{l}72.0 \\
71.7\end{array}$ & $\begin{array}{l}\text { Ref } \\
0.98\end{array}$ & $(0.94-1.03)$ & 0.463 & $\begin{array}{r}\text { Ref } \\
0.97\end{array}$ & $(0.91-1.02)$ & 0.249 & $\begin{array}{l}\text { Ref } \\
0.97\end{array}$ & $(0.91-1.03)$ & 0.258 \\
\hline \multicolumn{11}{|l|}{ Age } \\
\hline $\begin{array}{l}16-24(n=233) \\
25-34(n=634) \\
35-44(n=2099) \\
45-54(n=5676) \\
55-64(n=10744) \\
65-74(n=13028) \\
75-84(n=7533) \\
85+(n=1494)\end{array}$ & $\begin{array}{l}59.1 \\
64.7 \\
63.9 \\
66.4 \\
73.0 \\
75.0 \\
72.6 \\
69.7\end{array}$ & $\begin{array}{l}0.48 \\
0.61 \\
0.59 \\
0.66 \\
0.90 \\
\text { Ref } \\
0.88 \\
0.77\end{array}$ & $\begin{array}{l}(0.37-0.63) \\
(0.52-0.72) \\
(0.53-0.65) \\
(0.62-0.70) \\
(0.85-0.95) \\
(0.83-0.94) \\
(0.68-0.86)\end{array}$ & $<0.001$ & $\begin{array}{l}0.49 \\
0.59 \\
0.56 \\
0.63 \\
0.88 \\
\text { Ref } \\
0.90 \\
0.79\end{array}$ & $\begin{array}{l}(0.37-0.64) \\
(0.49-0.70) \\
(0.51-0.62) \\
(0.59-0.68) \\
(0.83-0.94) \\
(0.84-0.96) \\
(0.70-0.88)\end{array}$ & $<0.001$ & $\begin{array}{l}0.49 \\
0.59 \\
0.56 \\
0.63 \\
0.88 \\
\text { Ref } \\
0.90 \\
0.79\end{array}$ & $\begin{array}{l}(0.37-0.65) \\
(0.49-0.70) \\
(0.50-0.62) \\
(0.58-0.67) \\
(0.83-0.94) \\
(0.84-0.96) \\
(0.70-0.89)\end{array}$ & $<0.001$ \\
\hline \multicolumn{11}{|l|}{ Ethnicity } \\
\hline $\begin{array}{l}\text { White }(n=39809) \\
\text { Mixed }(n=180) \\
\text { South Asianc }(n=696) \\
\text { Black }(n=607) \\
\text { Chinese }(n=97) \\
\text { Other }(n=52)\end{array}$ & $\begin{array}{l}72.3 \\
62.2 \\
63.5 \\
55.5 \\
59.8 \\
59.6\end{array}$ & $\begin{array}{l}\text { Ref } \\
0.63 \\
0.67 \\
0.48 \\
0.57 \\
0.56\end{array}$ & $\begin{array}{l}(0.47-0.85) \\
(0.57-0.78) \\
(0.41-0.56) \\
(0.38-0.85) \\
(0.32-0.98)\end{array}$ & $<0.001$ & $\begin{array}{l}\text { Ref } \\
0.73 \\
0.73 \\
0.52 \\
0.62 \\
0.64\end{array}$ & $\begin{array}{l}(0.54-1.00) \\
(0.62-0.86) \\
(0.44-0.62) \\
(0.41-0.94) \\
(0.36-1.11)\end{array}$ & $<0.001$ & $\begin{array}{l}\text { Ref } \\
0.73 \\
0.75 \\
0.54 \\
0.63 \\
0.66\end{array}$ & $\begin{array}{l}(0.53-0.99) \\
(0.64-0.88) \\
(0.45-0.64) \\
(0.42-0.95) \\
(0.38-1.16)\end{array}$ & $<0.001$ \\
\hline \multicolumn{11}{|c|}{ Socioeconomic deprivation } \\
\hline $\begin{array}{l}\text { Least deprived }(n=9396) \\
\text { 2nd quintile }(n=9430) \\
\text { 3rd quintile }(n=8772) \\
\text { 4th quintile }(n=7525) \\
\text { Most deprived ( } n=6318)\end{array}$ & $\begin{array}{l}72.8 \\
73.0 \\
71.2 \\
71.6 \\
70.0\end{array}$ & $\begin{array}{l}\text { Ref } \\
1.01 \\
0.92 \\
0.94 \\
0.87\end{array}$ & $\begin{array}{l}(0.95-1.08) \\
(0.87-0.99) \\
(0.88-1.01) \\
(0.81-0.94)\end{array}$ & $<0.001$ & $\begin{array}{l}\text { Ref } \\
1.01 \\
0.93 \\
0.98 \\
0.94\end{array}$ & $\begin{array}{l}(0.95-1.08) \\
(0.87-0.99) \\
(0.92-1.05) \\
(0.88-1.01)\end{array}$ & $<0.001$ & $\begin{array}{l}\text { Ref } \\
1.01 \\
0.93 \\
0.98 \\
0.94\end{array}$ & $\begin{array}{l}(0.95-1.08) \\
(0.87-0.99) \\
(0.91-1.05) \\
(0.87-1.01)\end{array}$ & $<0.046$ \\
\hline \multicolumn{11}{|l|}{ Cancer type } \\
\hline $\begin{array}{l}\text { Breast } \\
\text { Breast }(n=10366)\end{array}$ & 72.3 & 0.81 & $(0.73-0.88)$ & $<0.001$ & 0.94 & $(0.85-1.04)$ & $<0.001$ & 0.94 & $(0.85-1.04)$ & $<0.001$ \\
\hline $\begin{array}{l}\text { CNS } \\
\text { Brain }(n=300) \\
\text { Other CNS }(n=85)\end{array}$ & $\begin{array}{l}69.7 \\
72.9\end{array}$ & $\begin{array}{l}0.71 \\
0.83\end{array}$ & $\begin{array}{l}(0.55-0.92) \\
(0.51-1.35)\end{array}$ & $<0.001$ & $\begin{array}{l}0.88 \\
0.96\end{array}$ & $\begin{array}{l}(0.67-1.14) \\
(0.59-1.56)\end{array}$ & $<0.001$ & $\begin{array}{l}0.85 \\
0.96\end{array}$ & $\begin{array}{l}(0.65-1.10) \\
(0.58-1.57)\end{array}$ & $<0.001$ \\
\hline $\begin{array}{l}\text { Colorectal } \\
\text { Colon }(n=3225) \\
\text { Rectal }(n=2290) \\
\text { Anal }(n=145) \\
\text { Other colorectal }(n=139) \\
\text { Gynaecological } \\
\text { Ovarian }(n=1165) \\
\text { Uterine }(n=798) \\
\text { Cervical }(n=266) \\
\text { Vulvo-vaginal }(n=147) \\
\text { Other gynaecological } \\
(n=38)\end{array}$ & $\begin{array}{l}76.5 \\
70.2 \\
61.3 \\
69.8 \\
70.1 \\
79.0 \\
65.4 \\
78.2 \\
73.7\end{array}$ & $\begin{array}{l}\text { Ref } \\
0.73 \\
0.49 \\
0.71 \\
0.72 \\
1.15 \\
0.58 \\
1.11 \\
0.86\end{array}$ & $\begin{array}{l}(0.64-0.82) \\
(0.35-0.69) \\
(0.49-1.03) \\
(0.62-0.84) \\
(0.96-1.39) \\
(0.45-0.76) \\
(0.74-1.65) \\
(0.42-1.78)\end{array}$ & $<0.001$ & $\begin{array}{l}\text { Ref } \\
0.73 \\
0.52 \\
0.73 \\
\\
0.77 \\
1.20 \\
0.79 \\
1.19 \\
1.00\end{array}$ & $\begin{array}{l}(0.65-0.82) \\
(0.37-0.74) \\
(0.50-1.06) \\
(0.66-0.90) \\
(0.99-1.45) \\
(0.60-1.03) \\
(0.79-1.78) \\
(0.48-2.09)\end{array}$ & $<0.001$ & $\begin{array}{l}\text { Ref } \\
0.73 \\
0.52 \\
0.74 \\
0.77 \\
1.18 \\
0.76 \\
1.16 \\
0.99\end{array}$ & $\begin{array}{l}(0.65-0.82) \\
(0.37-0.74) \\
(0.51-1.07) \\
(0.66-0.89) \\
(0.97-1.43) \\
(0.58-1.01) \\
(0.77-1.73) \\
(0.47-2.06)\end{array}$ & $<0.001$ \\
\hline $\begin{array}{l}\text { Haematological } \\
\text { Non-Hodgkin's lymphoma } \\
(n=2381) \\
\text { Myeloma }(n=1873) \\
\text { Leukaemia }(n=1650) \\
\text { Hodgkin's disease }(n=320) \\
\text { Other haematological } \\
(n=88)\end{array}$ & $\begin{array}{l}69.2 \\
66.3 \\
72.4 \\
62.8 \\
71.6\end{array}$ & $\begin{array}{l}0.69 \\
0.61 \\
0.81 \\
0.52 \\
0.78\end{array}$ & $\begin{array}{l}(0.61-0.78) \\
(0.53-0.69) \\
(0.71-0.93) \\
(0.41-0.66) \\
(0.48-1.24)\end{array}$ & $<0.001$ & $\begin{array}{l}0.72 \\
0.61 \\
0.89 \\
0.73 \\
0.88\end{array}$ & $\begin{array}{l}(0.64-0.81) \\
(0.54-0.70) \\
(0.77-1.02) \\
(0.57-0.94) \\
(0.55-1.41)\end{array}$ & $<0.001$ & $\begin{array}{l}0.72 \\
0.61 \\
0.88 \\
0.74 \\
0.87\end{array}$ & $\begin{array}{l}(0.64-0.81) \\
(0.54-0.69) \\
(0.77-1.01) \\
(0.57-0.95) \\
(0.54-1.40)\end{array}$ & $<0.001$ \\
\hline $\begin{array}{l}\text { Head and neck } \\
\text { Other head and neck } \\
(n=804) \\
\text { Thyroid }(n=289) \\
\text { Laryngeal }(n=242)\end{array}$ & $\begin{array}{l}71.3 \\
68.5 \\
74.0\end{array}$ & $\begin{array}{l}0.76 \\
0.67 \\
0.87\end{array}$ & $\begin{array}{l}(0.64-0.91) \\
(0.52-0.87) \\
(0.65-1.18)\end{array}$ & $<0.001$ & $\begin{array}{l}0.82 \\
0.87 \\
0.87\end{array}$ & $\begin{array}{l}(0.69-0.98) \\
(0.66-1.13) \\
(0.64-1.17)\end{array}$ & $<0.001$ & $\begin{array}{l}0.80 \\
0.84 \\
0.85\end{array}$ & $\begin{array}{l}(0.67-0.96) \\
(0.65-1.10) \\
(0.63-1.14)\end{array}$ & $<0.001$ \\
\hline $\begin{array}{l}\text { Lung } \\
\text { Lung }(n=2193) \\
\text { Mesothelioma }(n=231) \\
\text { Other thoracic }(n=34)\end{array}$ & $\begin{array}{l}72.0 \\
77.1 \\
67.7\end{array}$ & $\begin{array}{l}0.79 \\
1.03 \\
0.64\end{array}$ & $\begin{array}{l}(0.70-0.90) \\
(0.75-1.42) \\
(0.31-1.33)\end{array}$ & $<0.001$ & $\begin{array}{l}0.78 \\
0.98 \\
0.72\end{array}$ & $\begin{array}{l}(0.69-0.88) \\
(0.71-1.35) \\
(0.35-1.50)\end{array}$ & $<0.001$ & $\begin{array}{l}0.77 \\
0.97 \\
0.70\end{array}$ & $\begin{array}{l}(0.68-0.87) \\
(0.70-1.33) \\
(0.34-1.46)\end{array}$ & $<0.001$ \\
\hline $\begin{array}{l}\text { Other } \\
\text { Other }(n=244)\end{array}$ & 65.6 & 0.59 & $(0.44-0.77)$ & $<0.001$ & 0.62 & $(0.47-0.82)$ & $<0.001$ & 0.61 & $(0.46-0.80)$ & $<0.001$ \\
\hline
\end{tabular}




\section{Table 1. (Continued)}

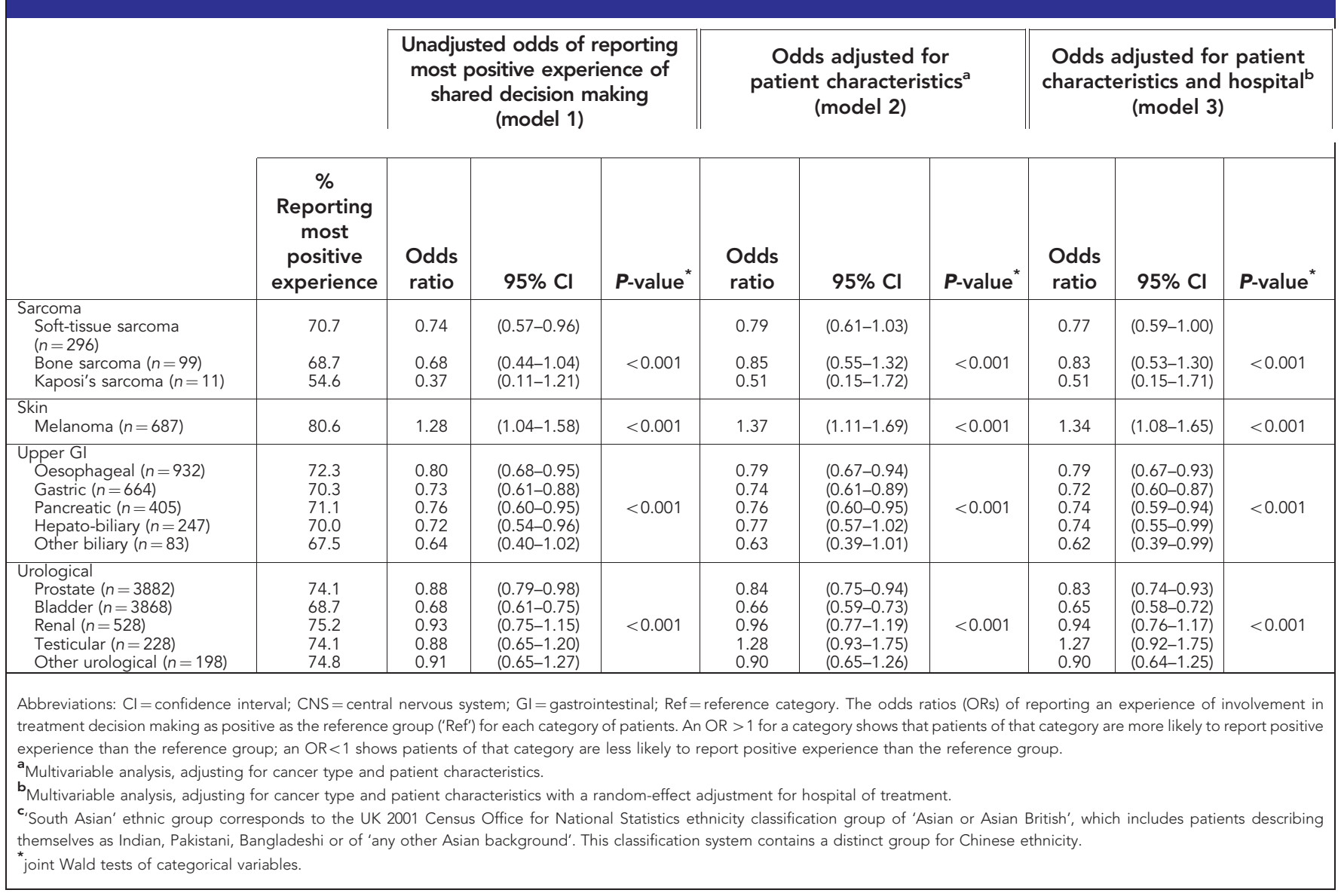

Finally, to assess potential bias that could have resulted by differential perception that 'only one treatment was suitable' between different patient groups, we compared the characteristics of respondents who were included and excluded from the analysis. We also performed two extreme case scenario sensitivity analyses whereby all excluded respondents were assumed to have provided informative responses, either all indicating a positive experience or all indicting a negative experience.

Significance was tested with joint Wald tests for categorical variables. All analyses were performed using Stata v12.0 (StataCorp, College Station, TX, USA).

\section{RESULTS}

A total of 101773 patients were invited to complete the survey and $67713(67 \%)$ responded. Of these, 64201 responded to the question regarding experience of involvement in decisions about treatment, of whom 48396 provided informative responses. Analysis was restricted to 41441 of these patients with a primary tumour diagnosis and complete sociodemographic data (Supplementary Appendix 3 and Supplementary Figure 1). Of these respondents, $29776(72 \%)$ reported the most positive experience of involvement in treatment decision making, 9197 (22\%) reported conditionally positive experience and 2468 (6\%) reported definitely negative experience.

In unadjusted analysis of different patient groups (model 1), there was very strong evidence of variation in experience of involvement in decision making about treatment between patients with different cancer types $(P<0.001$; Table 1$)$. Among the group

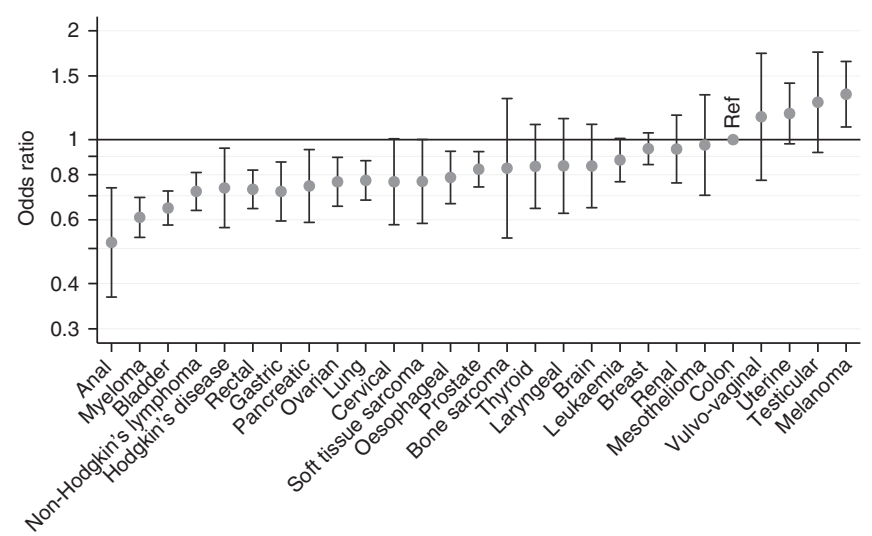

Figure 1. Adjusted odds ratios (with $95 \%$ confidence intervals) of reporting experience of involvement in decision making about treatment as positive as reference category for patients of different cancer types $(n=41441)$. Results adjusted for gender, age, ethnicity, socioeconomic deprivation, cancer type and a random effect for treating hospital (model 3). Ref = reference category. The odds ratio $>1$ suggests category more likely to report positive experience than reference category.

of most common cancers, patients with melanoma were substantially more likely to report the most positive experience than patients with other cancers (unadjusted OR melanoma $v s$ colon 1.28; $P<0.001$ ), whereas patients with anal cancers and myeloma reported the most negative experience (unadjusted OR vs colon 0.49 and 0.61 , respectively; $P<0.001$ ). There was no evidence of 
Table 2. Within-specialty variation of patient experience of involvement in decision making about treatment

\begin{tabular}{|c|c|c|}
\hline & $\begin{array}{l}\text { Adjusted odds ratio }{ }^{\text {a }} \text { (higher } \\
\text { values indicate more likely to } \\
\text { report positive experience } \\
\text { of shared decision making) }\end{array}$ & $95 \% \mathrm{Cl}$ \\
\hline \multicolumn{3}{|c|}{ Colorectal cancers } \\
\hline Colon & Ref & \\
\hline Rectal & 0.73 & $(0.65-0.82)$ \\
\hline Anal & 0.52 & $(0.37-0.74)$ \\
\hline \multicolumn{3}{|c|}{ Upper gastrointestinal cancers } \\
\hline Oesophageal & Ref & \\
\hline Gastric & 0.91 & $(0.73-1.14)$ \\
\hline Pancreatic & 0.95 & $(0.73-1.23)$ \\
\hline \multicolumn{3}{|c|}{ Urological cancers } \\
\hline Bladder & Ref & \\
\hline Prostate & 1.28 & $(1.16-1.42)$ \\
\hline Renal & 1.46 & $(1.18-1.80)$ \\
\hline Testicular & 1.96 & $(1.43-2.69)$ \\
\hline \multicolumn{3}{|c|}{ Gynaecological cancers } \\
\hline Ovarian & Ref & \\
\hline Cervical & 1.00 & $(0.75-1.33)$ \\
\hline Vulvo-vaginal & 1.51 & $(1.00-2.29)$ \\
\hline Uterine & 1.54 & $(1.25-1.91)$ \\
\hline \multicolumn{3}{|c|}{ Haematological cancers } \\
\hline Myeloma & Ref & \\
\hline $\begin{array}{l}\text { Non-Hodgkin's } \\
\text { lymphoma }\end{array}$ & 1.18 & $(1.03-1.34)$ \\
\hline Hodgkin's disease & 1.21 & $(0.93-1.56)$ \\
\hline Leukaemia & 1.44 & $(1.24-1.67)$ \\
\hline \multicolumn{3}{|c|}{$\begin{array}{l}\text { Abbreviations: } \mathrm{Cl}=\text { confidence interval; Ref }=\text { reference category. The odds ratios (ORs) of } \\
\text { reporting an experience of involvement in treatment decision making as positive as the } \\
\text { reference group ('Ref') for each category of patients. An } \mathrm{OR}>1 \text { for a category shows that } \\
\text { patients of that category are more likely to report positive experience than the reference } \\
\text { group; an } \mathrm{OR}<1 \text { shows patients of that category are less likely to report positive } \\
\text { experience than the reference group. } \\
\text { a'Multivariable analysis, adjusting for cancer type and patient age, gender, ethnicity, } \\
\text { socioeconomic deprivation and cancer diagnosis with a random effect adjustment for } \\
\text { hospital of treatment (derived from model 3). }\end{array}$} \\
\hline
\end{tabular}

differences in reported experience between sexes (unadjusted OR women vs men 0.98; $P=0.463)$. Between different age groups there was strong evidence of substantial variation $(P<0.001)$; patients in the $65-74$ age group reported the most positive experience, whereas younger patients reported substantially less positive experience (unadjusted OR 16-24 vs 65-74 0.48), as did patients older than the 65-74 age group (unadjusted OR $85+v s$ 65-74 0.77). There was strong evidence that patients from ethnic minorities were more likely to report a negative experience than White patients (unadjusted OR vs White: Black 0.48, Chinese 0.57 , South Asian $0.67 ; P<0.001$ ). Experience also varied between patients of differing socioeconomic backgrounds $(P<0.001)$, but the magnitude of this variation was small (unadjusted OR most deprived $v$ s least deprived 0.87 ).

Adjusting for all sociodemographic variables and cancer diagnosis produced highly similar findings for cancer, age, sex and ethnic variation (model 2), but variation by deprivation was attenuated such that there was only weak evidence of variation $(P=0.053)$. None of the above findings changed substantially when hospital of treatment was included as a random effect (model
3 - see Table 1 and Figure 1), suggesting that the observed variation was unlikely the result of clustering of certain patient groups into hospitals with higher or lower performance. There were only small differences in the demographic characteristics of cases who were excluded from the analysis (e.g., because they answered that only one treatment was suitable for them) (Supplementary Appendix 3 and Supplementary Figure 2). Furthermore, extreme case scenario sensitivity analyses about the potential impact of differential perception or recall of shared decision making produced similar findings for demographic variables to those observed in the main analysis (Supplementary Appendix 3 and Supplementary Table 1). Sensitivity analysis using alternative dichotomisation of our response variable produced broadly concordant findings (Supplementary Appendix 4).

Reported experience varied considerably between cancers treated by the same teams of specialists (estimates derived from model 3; Table 2). For example, patients treated for leukaemia reported substantially more positive experience of involvement in treatment decision making than patients with myeloma (adjusted $\mathrm{OR}=1.44$ leukaemia $v$ myeloma; $P<0.001$ ). Similar patterns of within-specialty variation were observed for colorectal, gynaecological and urological cancers, with patients with rectal, ovarian and bladder cancer reporting notably worse experience than patients with colon, uterine and renal cancers, respectively. There was no such variation for upper gastrointestinal cancers.

\section{DISCUSSION}

Our findings indicate that within the context of a national health service providing universal coverage, notable variations exist in experience of involvement in decision making about cancer treatment between patients with different cancers and of different ages and ethnicities. Large variations also exist in the experience of decision-making involvement between patients suffering from cancers of the same system treated within the same specialty service, for example, between patients with different gynaecological, haematological and urological cancers. These variations could not be explained by concentration of patients reporting more negative experiences in certain hospitals.

We know of no other national cancer patient survey including patients with such a broad range of cancers. The large number of participants allows us to examine relatively small patient groups, overcoming the limitations of previous smaller studies (Hubbard et al, 2008). The fact that the survey samples all patients nationally strengthens the generalisability of our findings. Significant limitations nevertheless exist in the use of patient survey data for any substantive inquiry into health service quality, including the lack of direct observation of patient care episodes and the effects of potential for nonresponse bias (including survivorship, participation and recall biases) (Lyratzopoulos et al, 2012b). Our study excluded respondents with missing sociodemographic data, those without a recorded primary cancer diagnosis and those who provided uninformative responses to the profiled question on shared decision making. However, comparison of the characteristics of respondents included and excluded from our analysis indicated little difference between these groups (Supplementary Appendix 3 and Supplementary Figure 2), suggesting limited potential for any bias that can result from such exclusions. Also, our data did not include variables on patients' native language or disease severity measures such as tumour stage or functional status, potentially important variables in understanding observed ethnic and tumour variation, respectively.

One limitation of the survey item analysed was the asymmetrical response options offered to respondents. Although respondents could indicate that they were insufficiently involved in decisions 
about treatment, there was no option for respondents to highlight dissatisfaction with over-involvement in treatment decision making. This may be an important omission given that previous studies examining patient preference for involvement in treatment decision making suggests a significant minority of patients prefer to adopt a passive role in treatment decision making and that involving these patients against their preference can provoke anxiety (Hack et al, 1994; Hubbard et al, 2008). It may be useful to develop survey questions that encompass a fuller spectrum of patient preferences for shared decision making in the future.

Another limitation of our study is that we are not able to assess whether doctors did indeed present all respondents with appropriate choice of treatment where such a choice was clinically appropriate (the consultation style of some treating clinicians may involve little shared decision making with the patient). We do however judge the potential for bias arising from such a source to be limited - particularly when considering differences between cancers treated by doctors of the same clinical specialty and multidisciplinary team. Furthermore, it was not possible to assess the extent to which the patients' perceptions concord with objective measures of involvement in treatment decision making. In principle, patients with certain characteristics may systematically perceive that only one type of treatment was suitable for them more or less often than patients with other characteristics, and this may result in bias. However, sensitivity analyses of the potential impact of excluding patients with uninformative responses provided similar findings to those observed in the main analysis.

Variation in reported experience of involvement in decision making between patients treated for different cancers may reflect differences in disease factors. Patients with melanoma and testicular cancer who reported the most positive experiences of decision-making involvement are also generally diagnosed promptly after symptomatic presentation and have relatively good prognoses (5-year relative survival $>80 \%$ ) (Coleman et al, 2004; Lyratzopoulos et al, 2012b). In contrast, patients with multiple myeloma who reported nearly the worst experience of decisionmaking involvement are likely to experience a delayed diagnosis, and have a relatively poor prognosis (5-year relative survival $<30 \%$ ) (Coleman et al, 2004; Lyratzopoulos et al, 2012b). There was also substantial variation in experience of decision-making involvement between patients with cancers treated by the same specialty but which present different diagnostic or treatment challenges or have variable functional outcomes and prognosis. For example, patients with colon cancer reported substantially more positive experiences of involvement in decision making than patients with rectal cancer. Although colon and rectal cancer share similar presentations and diagnostic pathways, they differ substantially with respect to treatment patterns and functional outcomes: in contrast with colon cancer patients, approximately two-thirds of patients with rectal cancer treated by surgery require stoma formation, which is permanent in at least a quarter of all patients (Finan et al, 2010). Greater evidential uncertainty about optimal treatment of some cancers such as prostate cancer, or greater intensity or complexity of treatment and surveillance protocols such as for non-Hodgkin's lymphoma, may create greater decisional conflict for patients and a less positive experience.

Patients with cancer who were $<55$ years old reported the most negative experience of involvement in treatment decision making; a finding consistent with evidence from many other patient surveys (Weech-Maldonado et al, 2003; Hubbard et al, 2008; Lyratzopoulos et al, 2012a). Young patients may have higher expectations of quality than older peers, related to less frequent use of health-care services (Weech-Maldonado et al, 2003; Hubbard et al, 2008; Lyratzopoulos et al, 2012a) and generational differences in expectations of autonomy (Benbassat et al, 1998; Gaston and Mitchell, 2005). Resultantly, younger patients may expect to be more involved than older peers in decisions about their treatment and more likely to report negative experience when these higher expectations are not met. It may also be that younger patients are treated differently to older patients by care providers, resulting in variable experiences of care between age groups. Patients in the oldest age groups (75-84 and 85+ years) also reported more negative experience than patients in the 65-74-year-old group. These may reflect communication difficulties experienced by doctors when engaging with patients of older age related to declining sensory and cognitive function in these patients. Nearly half of all cancers occur in patients aged $\geqslant 70$ years. It is therefore important to explore poor experience of decision-making involvement reported by older patients, particularly given concerns about suboptimal uptake of radical treatments among older patients who are otherwise fit (Department of Health, 2012).

Ethnic minority patients also reported poorer experience of involvement in decisions about treatment; a finding concordant with other studies examining patient experience of care more generally (Campbell et al, 2001; Weech-Maldonado et al, 2003; Goldstein et al, 2009; Mead and Roland, 2009; Elliott et al, 2010; Lyratzopoulos et al, 2012a) and cancer care specifically (Ayanian et al, 2010). These ethnic inequalities by and large did not reflect confounding by differences in age, gender, deprivation or cancer type. Nor were they explained by clustering of ethnic minority patients in hospitals with below-average patient experience scores; a finding in contrast to the hypothesis proposed by the English Department of Health in its analysis of the survey (Department of Health, 2010a). Service factors potentially responsible for ethnic disparities of experience have been proposed. Previous reports suggest an association between access to language and cultureappropriate services and greater engagement of ethnic minority patients in care processes (Gordon-Dseagu, 2006). Ethnic disparities of reported experience of care are greater for older patients from ethnic minorities than for younger patients from the same minorities, (Lyratzopoulos et al, 2012a), a finding consistent with a hypothesis of generational acculturation: younger generations, raised in the prevailing cultural context of the health system, are less affected by issues of language or cultural competence than older generations who are more likely to have migrated to the country of care as adults. Also, evidence from other cancer patient surveys suggests that native language explains some observed variation in patient experience reports (Ayanian et al, 2010).

The findings identify different groups of patients who are at greater risk of least positive experience of involvement in decision making. This profiling can help inform priorities about further research and improvement efforts. Research and improvement efforts could explore provision of additional consultation time with treating clinicians; greater access to cancer specialist nurses, supporting care professionals or peer support groups; and additional provision of decision aids and written information (Friedberg et al, 2013). Some of these improvement efforts can occur within the same specialty or service environments, focussing on patients who are likely to require additional resources or interventions in order to help improve their experience of shared decision making (e.g., providing additional decision-making support for patients with multiple myeloma, within the context of a haematological oncology service, or for patients with ovarian cancer within the context of gynaecological cancer services).

Similarly, research and improvement efforts could prioritise exploring the usefulness of additional support for younger and ethnic minority patients with cancer. For patients with cancer from ethnic minority groups, exploring the usefulness of provision of translational services or translated written material, or interventions that aim to increase the cultural awareness of care providers, may also be justified. 
The findings also advocate for the need to use case-mix adjustment of hospital performance of cancer patient experience measures (O'Malley et al, 2005). This is because using unadjusted (not case-mix adjusted) hospital scores may inadvertently and unfairly penalise (or be perceived to unfairly penalise) cancer centres that specialise in care of patients who face the biggest challenges in terms of shared decision making, such as ovarian cancer or myeloma patients, or younger patients with cancer. Simultaneously reporting both crude and case-mix adjusted performance may be ideal.

In conclusion, we report large variation in the experience of involvement in decisions about treatment between patients with 38 different cancers and different sociodemographic characteristics. Further qualitative research involving patients and clinicians is justified to generate and test hypotheses regarding causal mechanisms of observed disparity to help improve care. Additionally, quantitative research examining potential associations between disease severity and patient-reported experience is also needed. In future, better linkage of patient experience and patientlevel clinical data, especially data regarding disease severity and functional status, would allow for an improved understanding of how disease state influences patient reports of experience of shared decision making (and other aspects of care). Furthermore, greater use of paired report-evaluation questions would allow a better understanding of the role of differing patient expectations on observed variation in reported experience (Mead and Roland, 2009). Interventions and improvement initiatives can particularly focus on patients at higher risk of a less positive experience of decision-making involvement, such as patients at either extreme of the age spectrum, ethnic minorities and patients with ovarian, bladder, myeloma and rectal cancers.

\section{ACKNOWLEDGEMENTS}

We are grateful to Tim Eisen for comments on an earlier draft of the manuscript. We thank the UK Data Archive for access to the anonymous survey data (UKDA study number: 6742), the Department of Health as the depositor and principal investigator of the Cancer Patient Experience Survey 2010, Quality Health as data collector and all NHS Acute Trusts in England for provision of data samples. We also thank all patients who responded to the survey. AET is funded by an Academic Clinical Fellowship award from the National Institute for Health Research. GL is funded by a Post-Doctoral Research Fellowship award from the National Institute for Health Research.

\section{DISCLAIMER}

This is an independent research paper and the views expressed herein are those of the authors and not necessarily those of the NHS, National Institute for Health Research or Department of Health.

\section{REFERENCES}

Ayanian JZ, Zaslavsky AM, Arora NK, Kahn KL, Malin JL, Ganz Pa, Ryn M, van, Hornbrook MC, Kiefe CI, He Y, Urmie JM, Weeks JC, Harrington DP (2010) Patients' experiences with care for lung cancer and colorectal cancer: findings from the Cancer Care Outcomes Research and Surveillance Consortium. J Clin Oncol 28: 4154-4161.

Barry MJ, Edgman-Levitan S (2012) Shared decision making-pinnacle of patient-centered care. $N$ Engl J Med 366: 780-781.
Benbassat J, Pilpel D, Tidhar M (1998) Patients' preferences for participation in clinical decision making: a review of published surveys. Behav Med 24: 81-88.

Brown R, Butow P, Wilson-Genderson M, Bernhard J, Ribi K, Juraskova I (2012) Meeting the decision-making preferences of patients with breast cancer in oncology consultations: impact on decision-related outcomes J Clin Oncol 30: 857-862.

Campbell JL, Ramsay J, Green J (2001) Age, gender, socioeconomic, and ethnic differences in patients' assessments of primary health care. Qual Health Care 10: 90-95.

Coleman MP, Rachet B, Woods LM, Mitry E, Riga M, Cooper N, Quinn MJ, Brenner H, Estève J (2004) Trends and socioeconomic inequalities in cancer survival in England and Wales up to 2001. Br J Cancer 90: 1367-1373.

Committee On Quality Of Health Care In America (2001) Crossing the Quality Chasm: A New Health System for the 21st Century. National Academy Press: Washington, DC.

Department of Health (2010a) National Cancer Patient Experience Survey Programme - 2010 National Survey Report. Department of Health: London.

Department of Health (2010b) National Cancer Patient Experience Survey 2010 [computer file]. UK Data Archive [distributor]: Colchester.

Department of Health (2012) The Impact of Patient Age on Clinical DecisionMaking in Oncology. Department of Health: London.

Elliott MN, Lehrman WG, Goldstein E, Hambarsoomian K, Beckett MK, Giordano La (2010) Do hospitals rank differently on HCAHPS for different patient subgroups? Med Care Res Rev 67: 56-73.

Epstein R, Street RJ (2007) Patient-Centered Communication in Cancer Care: Promoting Healing and Reducing Suffering. National Institutes if Health: Bethesda.

Finan P, Smith J, Trivella M, Meulan J, van der, Greenaway K, Yelland A (2010) National Bowel Cancer Audit. NHS Information Centre: Leeds.

Friedberg MW, Van Busum K, Wexler R, Bowen M, Schneider EC (2013) A demonstration of shared decision making in primary care highlights barriers to adoption and potential remedies. Health Aff 32: 268-275.

Gaston CM, Mitchell G (2005) Information giving and decision-making in patients with advanced cancer: a systematic review. Soc Sci Med 61: 2252-2264.

Gattellari M, Butow PN, Tattersall MH (2001) Sharing decisions in cancer care. Soc Sci Med 52: 1865-1878.

Goldstein E, Elliott MN, Lehrman WG, Hambarsoomian K, Giordano La (2009) Racial/ethnic differences in patients' perceptions of inpatient care using the HCAHPS survey. Med Care Res Rev 67: 74-92.

Gordon-Dseagu V (2006) Cancer and Health Inequalities: An Introduction to Current Evidence. Cancer Research UK: London.

Hack TF, Degner LF, Dyck DG (1994) Relationship between preferences for decisional control and illness information among women with breast cancer: a quantitative and qualitative analysis. Soc Sci Med 39: 279-289.

Hubbard G, Kidd L, Donaghy E (2008) Preferences for involvement in treatment decision making of patients with cancer: a review of the literature. Eur J Oncol Nurs 12: 299-318.

Keating NL, Guadagnoli E, Landrum MB, Borbas C, Weeks JC (2002) Treatment decision making in early-stage breast cancer: should surgeons match patients' desired level of involvement? J Clin Oncol 20: 1473-1479.

Lyratzopoulos G, Elliott M, Barbiere JM, Henderson A, Staetsky L, Paddison C, Campbell J, Roland M (2012a) Understanding ethnic and other socio-demographic differences in patient experience of primary care: evidence from the English General Practice Patient Survey. BMJ Qual Saf 21: $21-29$

Lyratzopoulos G, Neal RD, Barbiere JM, Rubin GP, Abel Ga (2012b) Variation in number of general practitioner consultations before hospital referral for cancer: findings from the 2010 National Cancer Patient Experience Survey in England. Lancet Oncol 13: 353-365.

Mead N, Roland M (2009) Understanding why some ethnic minority patients evaluate medical care more negatively than white patients: a cross sectional analysis of a routine patient survey in English general practices. BMJ 339: b3450.

Noble M, McLennan D, Wilkinson K, Whitworth A, Barnes H, Dibben C (2007) The English Indices of Deprivation. Department of Communities and Local Government: London.

O’Malley AJ, Zaslavsky AM, Elliott MN, Zaborski L, Cleary PD (2005) Case-mix adjustment of the CAHPS Hospital Survey. Health Serv Res 40: 2162-2181. 
Quality Health (2010a) National Cancer Patient Experience Survey 2010 - Trust Level Reports. Deaprtment of Health: London. http:// www.quality-health.co.uk/cancer-reports (accessed 12 May 2013).

Quality Health (2010b) National Cancer Patient Experience Survey

Programme - Cognitive Testing Report 2010. Quality Health: Chesterfield. http://www.esds.ac.uk/doc/6742/mrdoc/pdf/

ncpes_2010_cognitive_testing_report.pdfaccessed 12 May 2013.

Rodriguez HP, Scoggins JF, Glahn T, von, Zaslavsky AM, Safran DG (2009) Attributing sources of variation in patients' experiences of ambulatory care. Med Care 47: 835-841.

Secretary of State for Health (2010) Equity and excellence: liberating the NHS. HMSO: London.
Stiggelbout aM, Weijden TVD, Wit MPTD, Frosch D, Legare F, Montori VM, Trevena L, Elwyn G (2012) Shared decision making: really putting patients at the centre of healthcare. BMJ 344: e256-e256.

Weech-Maldonado R, Morales LS, Elliott M, Spritzer K, Marshall G, Hays RD (2003) Race/ethnicity, language, and patients' assessments of care in Medicaid managed care. Health Serv Res 38: 789-808.

cc)(1)(2) This work is licensed under the Creative Commons Attribution-NonCommercial-Share Alike 3.0 Unported License. To view a copy of this license, visit http://creativecommons. org/licenses/by-nc-sa/3.0/

Supplementary Information accompanies this paper on British Journal of Cancer website (http://www.nature.com/bjc) 